
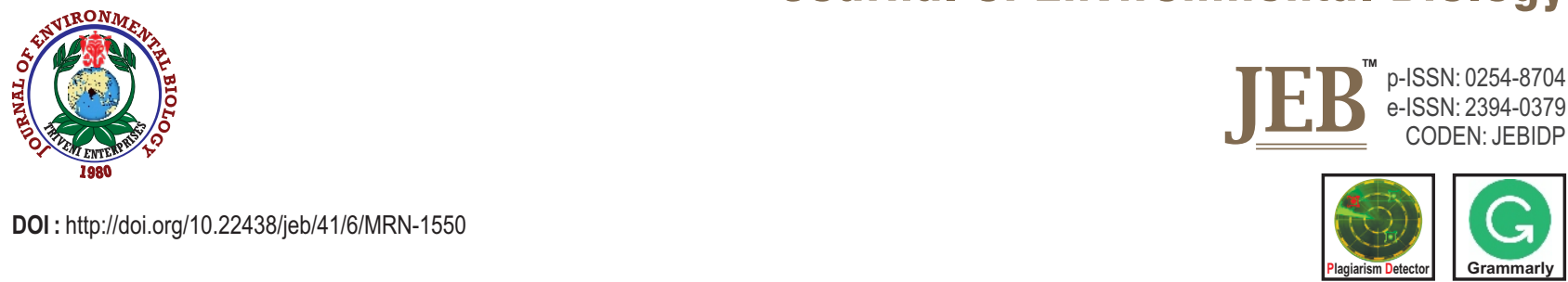

\title{
Antibacterial activity of selected plants extract against pathogenic bacteria and detection of phytochemicals
}

\author{
A. Saxena ${ }^{1}$, A.K. Mukhopadhyay ${ }^{2}$ and S.P. Nandi ${ }^{1 *}$ \\ ${ }^{1}$ Amity Institute of Biotechnology, Amity University, Noida-201 313, India \\ ${ }^{2}$ Bacteriology Division, ICMR-National Institute of Cholera and Enteric Diseases, Kolkatta-700 010, India \\ *Corresponding Author Email : spaul@amity.edu
}

\section{Abstract}

Aim: The aim of the present study was to assess the antibacterial activity of selected plants extract against Gram- positive and Gram- negative pathogenic bacteria.

Methodology: Extracts of neem leaf (Azadirachta indica), rose petal (Rosa indica), amla fruit (Emblica officinalis) and clove buds (Syzygium aromaticum) were prepared in different solvents. Antibacterial activity against selected microorganisms was assayed using agar cup diffusion method, thereby measuring the zone of inhibition. The extracts with higher zone of inhibition were run on Thin Layer Chromatography (TLC) plates. The presence of phytochemicals was detected using iodine fumigation method followed by contact bioautography.

Results: The extracts of neem leaf, rose petal, amla fruit and clove bud prepared in solvents like acetone, ethanol and ethyl acetate showed higher antibacterial effect against Staphylococcus aureus, Streptococcus pyogenes, Escherichia coli, Klebsiella pneumoniae and Salmonella typhimurium in agar cup diffusion assay. TLC separation of the extract of plant products showed dark brown bands of phytochemicals on silica-gel G 60 plate. Contact bioautography results showed maximum antibacterial activity against Klebsiella pneumoniae.
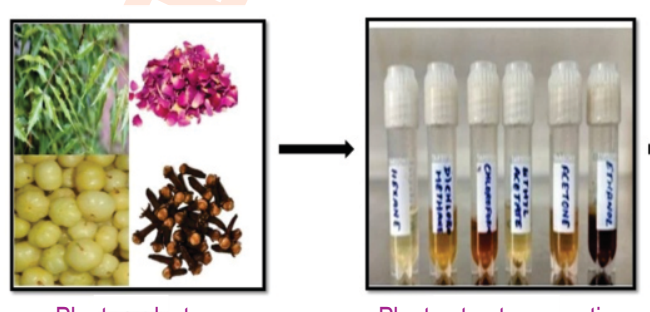

Plant extract preparation

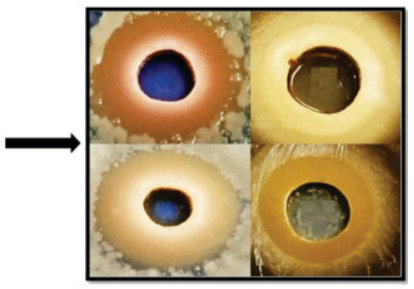

Antibacterial activity detected by Agar Cup Bioassay

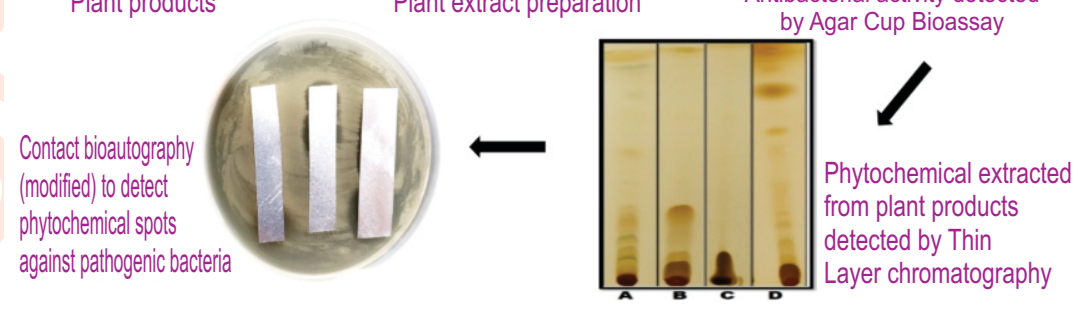

Interpretation: The results of the present study provide scientific evidence for the traditional uses of Azadirachta indica, Rosa indica, Emblica officinalis and Syzygium aromaticum.

Key words: Agar cup diffusion assay, Antibacterial activity, Contact bioautography, Pathogenic bacteria, Phytochemicals

How to cite : Saxena, A., A.K. Mukhopadhyay and S.P. Nandi: Antibacterial activity of selected plants extract against pathogenic bacteria and detection of phytochemicals. J. Environ. Biol., 41, 1486-1492 (2020). 


\section{Introduction}

Interest in the study of various medicinal plants has increased globally during last few decades, may be due to their antibacterial and antioxidant activities, low toxicity and comparatively cheaper to synthetic drugs (Chew et al., 2012). The determination of antibacterial activities of different medicinal plants is of special interest due to the current global issue of increasing antibiotic resistance of microorganisms (Farjana et al., 2014). The most important of these bioactive compounds are alkaloids, flavonoids, tannins, and phenolic compounds. Plants produce secondary metabolites that possess effective pharmacological activity (Raja and Sreenivasulu, 2015). Flavonoids with dominant antimicrobial activities act via microbial cell membranes and interacts with bacterial cell membrane protein of both Gram-positive and Gram-negative organisms (Upadhyay et al., 2014). Medicinal importance of plants has been used in various countries all over the globe. These medicinal plants have been a source of many powerful, effective and potent drugs (Srivastava et al., 1996).

Pathogenic bacteria such as Staphyllococcus aureus, Streptococcus pyogenes, Escherichia coli, Klebsiella pneumoniae and Salmonella typhimurium are the basic cause of many diseases in animals and humans. It is elaborated that death provoking pathogens are often unidentified or arise in mixed infections with more than one pathogenic agent (Hessling et al., 2017). A list of globally most important pathogens was generated based on the causes of death, and this statistics was published in the Global Burden Disease Study 2015 (Wang et al., 2016). S. aureus, a Gram-positive bacterium is usually found on the skin and in the upper respiratory tract. It commonly causes bacteremia and infected endocarditis (Tong et al., 2015). S. pyogens is another Gram-positive bacterium that colonizes throat, rectum, skin and genital mucosa causing mild skin infections to fatal systemic diseases (Ryan and Ray, 2004). E. coli is a Gramnegative bacterium that inhabit the lower abdomen of warmblooded animals. The majority of the E. coli strains do not cause any disease, but the virulent strains cause neonatal meningitis, urinary tract infection, and Crohn's disease (Todar, 2007; Lim et al., 2010). K. pneumonia, a Gram-negative bacterium is found in the normal flora of skin, mouth and intestine (Ryan and Ray, 2004). It commonly causes of pneumonia. S. typhimurium is another Gram-negative bacterium, mainly found in the intestinal lumen, causing gastroenteritis in humans and other mammals (Everest, 1999).

According to World Health Organization, $80 \%$ of the world population depends on herbal medicines for their primary health care needs International Union for Conservation of Nature \& World Wildlife Fund (1993). Globally over $40 \%$ of the population is dependent directly on plant-based medicines (Jagatheeswari et al., 2013). Azadirachta indica commonly known as neem is a potent medicinal plant with multiple biological activities of its various parts against many pathogenic strains that possess antibacterial activities, antiviral and antifungal properties
(Atawodi and Atawodi, 2009). The neem plant has been reported having more than 135 bioactive compounds isolated (Girish and Bhat, 2008). Recently Uzzaman 2019 has reviewed wide range of medicinal activities of neem (Azadirachta indica) plant. The leaves and petals Rosa indica or Rose are found effective against fever, diuretic, bronchial congestion, cold and sore throat.

There have been very few reports on the antibacterial activity of rose, but rose water and oil have been found effective against eye and skin irritation (Koday et al. 2010; Sahoo et al., 2011). Numerous beneficial biological properties make Emblica officinalis or Amla, an important plant for herbal drugs. Amla fruit a super-rich source of vitamin $C$ is used against a variety of clinical manifestations (Majeed et al., 2009). Syzygium aromaticum or Clove is reported having properties against bacterial diseases and also as fragrance and flavor (Saeed and Tariq, 2008). The determination of antibacterial activities of different medicinal plants is of special interest these days due to the current global issue of increasing antibiotic resistance of microorganisms. The objective of the present study therefore was to assess the antibacterial activities of neem leaf (Azadirachta indica), rose petal (Rosa indica), amla fruit (Emblica officinalis) and clove buds (Syzygium aromaticum) against selected Gram-positive and Gram-negative pathogens.

\section{Materials and Methods}

Plant materials: Fresh leaves of $A$. indica, petals of $R$. indica, and fruits of $E$. officinalis were collected from University of Agriculture and Technology, Faizabad. S. aromaticum buds were purchased from the local vendor in Ghaziabad The leaves of neem and petals of rose were separated from the stem and airdried for 3-4 days till constant weight was obtained. They were regularly examined to check any fungal growth or rotting. The fruit pulp of $E$. officinalis was also dried at room temperature. Dried plant materials were stored in paper bags and labelled properly.

Extraction of plant materials: Dried plant materials were crushed and soaked in hexane in a sterile conical flask and placed in an incubator at $37^{\circ} \mathrm{C}$ with continuous shaking for $24 \mathrm{hr}$. The content was filtered using Whatman filter paper No. 1 and the residues were re-soaked in dichloromethane for the next $24 \mathrm{hr}$ followed by chloroform, ethyl acetate, acetone and ethanol. Filtrates were concentrated to dryness; weight was taken, dissolved in respective solvents, and then stored in a sterile glass vial at $4^{\circ} \mathrm{C}$ until used.

Microorganisms and maintenance: Gram-positive bacteria used in this study were Streptococcus pyogenes (ATCC 19615) and Staphylococcus aureus (MTCC 96), while the Gram-negative bacteria were Escherichia coli (MTCC 739), Klebsiella pneumoniae and Salmonella typhimuriam (ATCC 14028). Luria Bertani (LB) agar (HiMedia) was used to maintain all the bacteria other than Streptococcus pyogenes, for which Trypticase Soy Agar (TSA-HiMedia) was used. The bacteria were maintained at $4^{\circ} \mathrm{C}$ and cultured in broth at $37^{\circ} \mathrm{C}$. 
Agar Cup Assay: The LB agar plates for Staphylococcus aureus, Escherichia coli, Salmonella typhimurium, Klebsiella pneumoniae were prepared and TSA for Streptococcus pyogenes was also prepared. The bacteria were cultured in their respective broths, labelled carefully and kept in an incubatorshaker at $37^{\circ} \mathrm{C}$ overnight. In an aseptic environment, the inoculum was spread on the agar plate of each bacteria. With the help of a sterile cork borer cups were made in each petri plate. The concentrated plant extract was pipetted in each cup.The same amount of solvent was also pipetted in one of the cups and was treated as control. These plates were then kept in an incubator for $24 \mathrm{hr}$ at $37^{\circ} \mathrm{C}$. After $24 \mathrm{hr}$, the plates were observed for the zone of inhibition that was calculated in mm (Bauer etal., 1966).

Thin Layer Chromatography: TLC Silica gel $60 \mathrm{~F}_{254}$ Aluminium sheet $20^{*} 20 \mathrm{~cm}$ (Merck, Germany) was used. Concentrated plant extracts (50 $\mu$ l each) were pipetted on this sheet. The sheet was left to air-dry overnight. The next day this sheet was dipped in Toluene:Chloroform:Acetone (40:25:35) solution. Faint bands appeared on TLC plate after the solvent run. TLC sheet was left to air-dry. Dry TLC sheets were put in a chamber containing lodine globules. Pink fumes started to emit. TLC sheet turned reddishbrown and the bands appeared (Lewis and Moody, 1989).

Contact Bioautography: The TLC sheet was cut into separate strips after lodine fumigation. The LB and TSA agar plates were prepared. The bacteria were cultured in their respective broths, labelled carefully and kept in an incubator-shaker at $37^{\circ} \mathrm{C}$ overnight. In an aseptic environment, the inoculum was spread on the agar plate of each bacterium. TLC chromatogram was carefully placed with face down onto the inoculated plates. These plates were left in an incubator at $37^{\circ} \mathrm{C}$ for $24 \mathrm{hr}$. The zone of inhibition was thereafter calculated in $\mathrm{mm}$.

Statistical Analysis: The experiment was conducted in triplicates and statistically analyzed for standard error.

\section{Results and Discussion}

The subcontinent of India is centre of possessing about 45000 plant species, out of which about 15000 have been

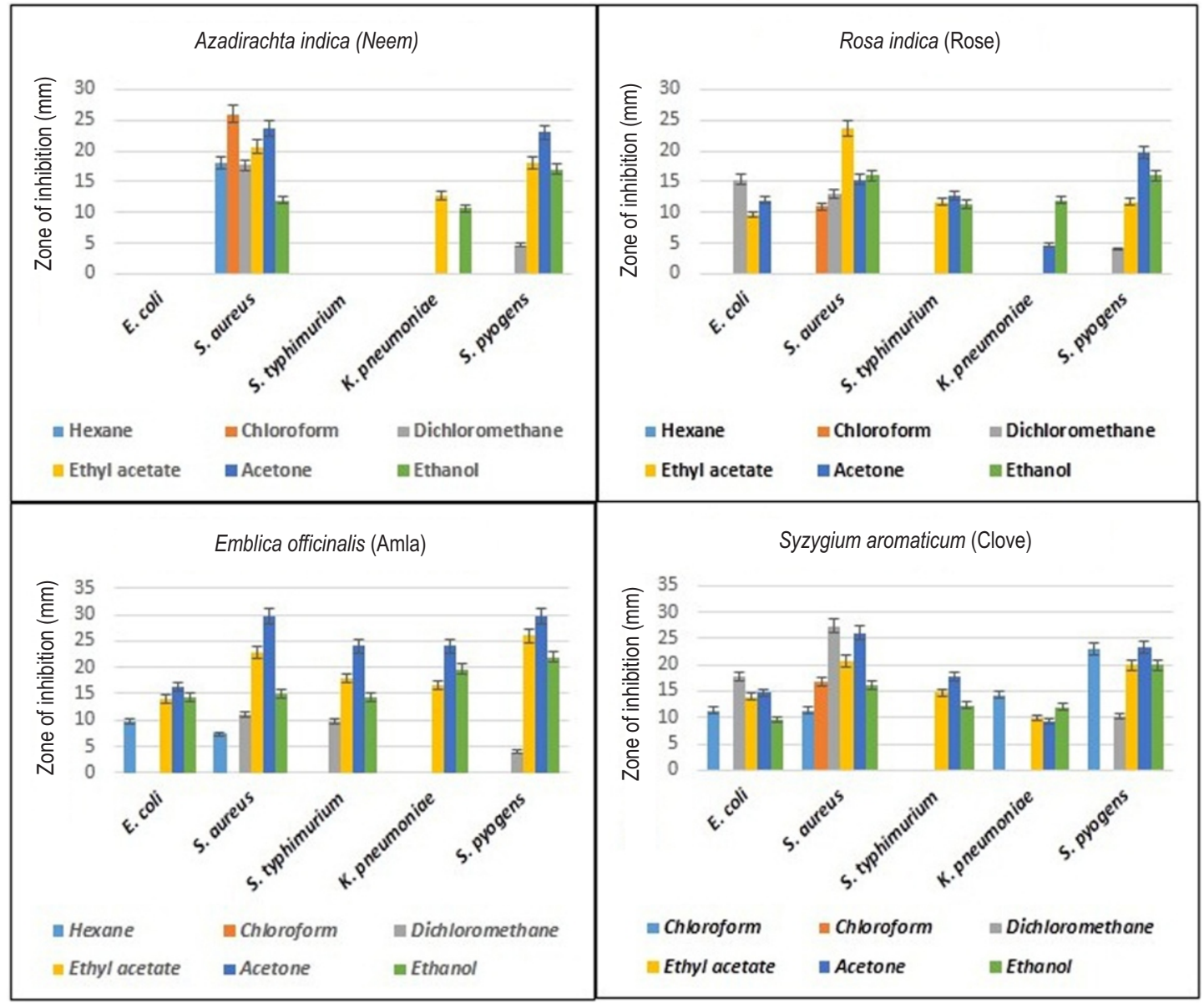

Fig. 1: Antibacterial activity of (A) Azadirachta indica (Neem);(B) Rosa indica (Rose); (C) Emblica officinalis (Amla) and (D) Syzygium aromaticum (Clove) solvent extracts against pathogenic bacteria, E. coli, S. aureus, S. typhimurium, K. pneumonia and S. pyogenes. 
Natural products

Pathogenic bacteria

Escherichia coli

ens

Staphylococcus aureus

Staphlococcus aureus

Salmonella typhimurium

Klebsiella pneumonia

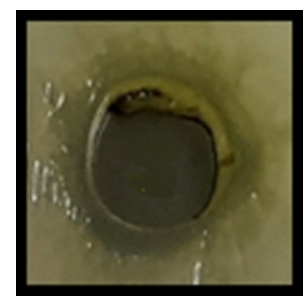

Ethanol

Streptococcus pyogenes

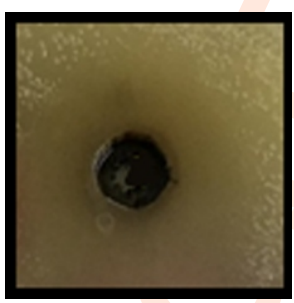

Ethyl Acetate

\section{Rosa indica}

(Rose)

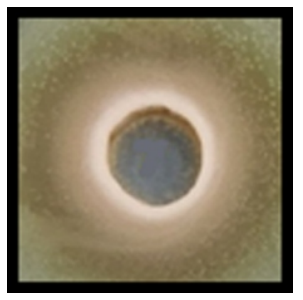

Acetone

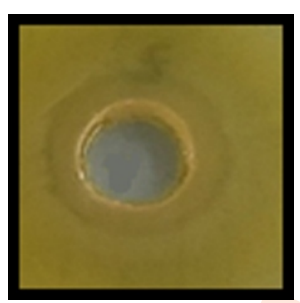

Ethyl Acetate

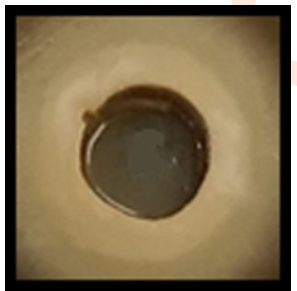

Acetone

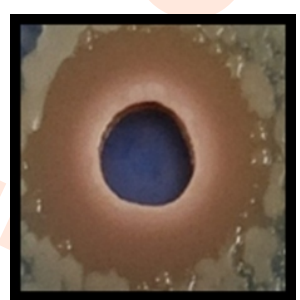

Ethanol

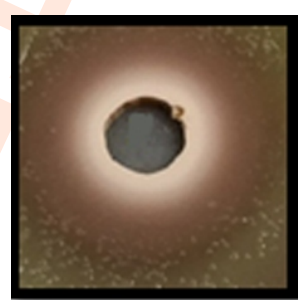

Ethyl Acetate
Emblica officinalis

(Amla)

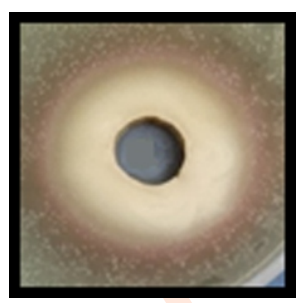

Acetone

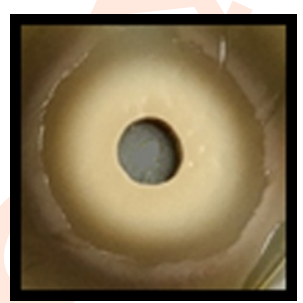

Ethyl Acetate

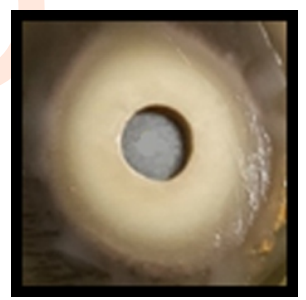

Acetone

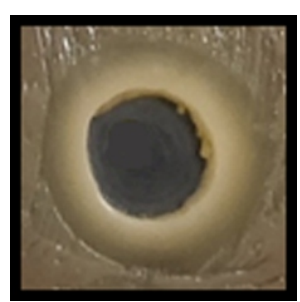

Ethanol

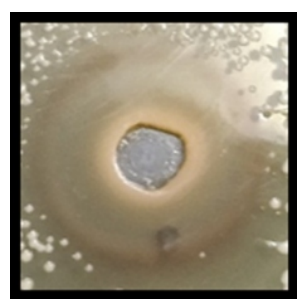

Ethyl Acetate
Syzygium aromaticum (Clove)

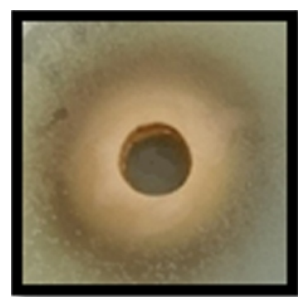

Acetone

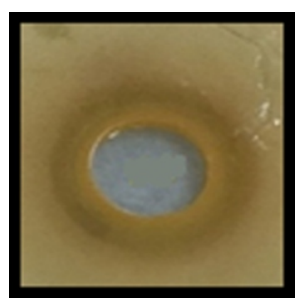

Ethyl Acetate

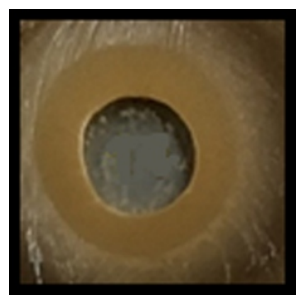

Acetone

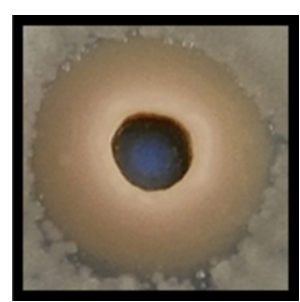

Ethanol

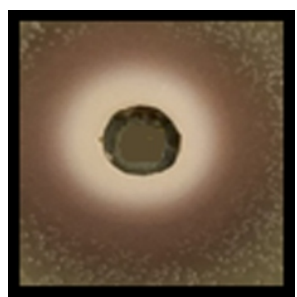

Ethyl Acetate

Fig. 2: Observation on Zone of Inhibition (Zol) as measured by agar cup diffusion assay of Azadirachta indica (Neem), Rosa indica (Rose), Emblica officinalis (Amla) and Syzygium aromaticum (Clove) extract prepared in ethanol, acetone and ethyl acetate extracts giving best results against pathogenic bacteria, E. coli, S. aureus, S. typhimurium, K. pneumonia and S. pyogenes.

recorded as medicinal plants (Parasuraman et al., 2014). In the present study, neem leaf extracts showed zone of inhibition (Fig. 1 A) against bacterial strains $S$. aureus in all the solvent used (12-26 $\mathrm{mm}), K$. pneumoniae in ethyl acetate and ethanol (10.67$12.67 \mathrm{~mm}$ ) and $S$. pyogenes in dichloromethane, ethyl acetate, acetone and ethanol (4.67 $-23 \mathrm{~mm}$ ), but it failed to produce zone 


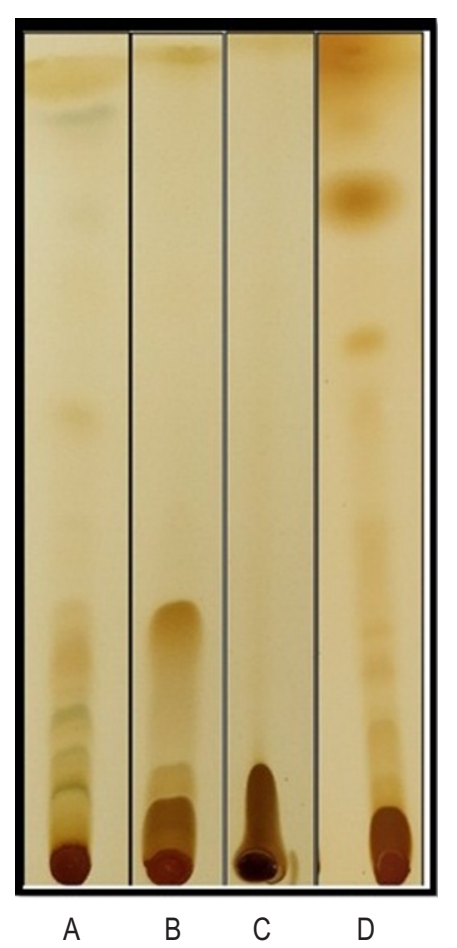

Fig. 3: Separation of the phytochemicals extracted from (A) Azadiracta indica (neem), (B) Rosa indica (rose ), (C) Emblica officinalis (amla) and (D) Syzygium aromaticum (clove), TLC containing silica-gel G 60 plate using toluene: chloroform: acetone (40:25:35) solution using iodine fumes.

of inhibition in E. coli and S. typhimurium irrespective of solvent. A study similar to the present study, reported that ethanolic neem leaves extract had growth hindrance effect on Salmonella and Klebsiella at concentrations of $6.2 \mathrm{mg} \mathrm{m}^{-1}$ and $12.5 \mathrm{mg} \mathrm{ml}^{-1}$ respectively. The average diameter of zone of inhibition was 18 $\mathrm{mm}$ for Klebsiella and $20 \mathrm{~mm}$ for Salmonella (Banna et al., 2014). It however failed to inhibit the growth of $S$. aureus at the highest concentration used that is $50 \mathrm{mg} \mathrm{ml}^{-1}$. The study thus suggested that, neem can be tried against Klebsiella and Salmonella. The ethyl acetate extractable fraction of neem leaves was inhibitory to the growth of $E$. coli 0157 in LB broth whereas Azadirachtin, a neem product having insect anti-feedant properties, failed to inhibit E. coli 0157 (Ravva and Korn 2015). Phytochemicals derived from the neem have also been reviewed for pharmacological effects such as anti-pyretic, anti-viral, analgesic, anti-bacterial, contraceptive and hepatoprotective activities (Nishan and Subramanian, 2014). Ethyl acetate, acetone and ethanol extracts of rose petals exhibited zone of inhibition to tested pathogens (Fig. 1B) in order S. aureus (11-23.67 mm), S. pyogenes $(11.67-19.67 \mathrm{~mm})$, E. coli $(9.67-15.33 \mathrm{~mm}) \mathrm{S}$. typhimurium (11.33-12.67 mm) and K. pneumoniae (4.67-12 $\mathrm{mm})$. The methanolic, ethanolic and distilled water extract of rose petals inhibited the common human pathogens.

The zone of inhibition was similar in the present study for the rose petal extracts prepared in ethyl acetate, acetone and ethanol (Fig. 1B) against E. coli, S. typhimurium, S. aureus, $S$. pyogenes and K. pneumonia (Laxmi etal., 2017). Rosa damascena petals extract in water, hexane and ethanol and further fractionation with chloroform, ethyl acetate and butanol exerted broad spectrum antimicrobial activities against the tested organisms for example $S$. aureus, Bacillus subtilis, S. pyogenes, Acinetobacter baumannii and K. pneumonia (Shohayeb et al., 2014). Amla extract prepared in ethyl acetate, acetone and ethanol had shown zone of inhibition $(14-29.67 \mathrm{~mm})$ against all the tested pathogens for ex. E. coli, S. aureus, S. typhimurium, K. pneumoniae and S. pyogenes (Fig. 1C). The inhibition was however not uniform in extracts prepared in hexane, dichloromethane and chloroform $(0-11 \mathrm{~mm})$. It has also been noted that amla extract prepared in acetone produced maximum inhibition $(29.67 \mathrm{~mm})$ in $S$. aureus and $S$. pyogenes. There are several reports on different degree of antimicrobial activity against some Gram negative and Gram positive pathogenic bacteria of the chloroform soluble fraction of the methanolic extract, aqueous extracts and aqueous infusion and decoction of amla (Rahman et al., 2009; Vijayalakshmi et al., 2007 and Saeed and Tariq 2007). Chloroform extract of amla in the present study has not shown inhibition against tested pathogens (Fig. 1C). Extracts of clove prepared in ethyl acetate, acetone and ethanol also induced zone of inhibition $(9.33-26.00 \mathrm{~mm}$ ) in all the tested pathogens (Fig. 1D) for example E. coli, S. aureus, S. typhimurium, K. pneumoniae and $S$. pyogenes. It is interesting to note that zone of inhibition was maximum $(27.33 \mathrm{~mm})$ against $S$. aureus with extract in dichloromethane followed by acetone $(26 \mathrm{~mm})$.

The antimicrobial activities of clove against several bacterial strains have been proved. Absolute bactericidal effect was seen when an aqueous extract of clove at $3 \%$ was tested against all the food-borne pathogens tested E. coli, S. aureus and Bacillus cereus. Good inhibitory action at the concentration of $1 \%$ clove extract was also reported (Sofia et al., 2007). According to a study suggested, clove oil inhibits the growth of $S$. aureus at molecular level. The authors of this study hypothesised that the mechanism involved was inhibition of DNA synthesis by clove oil entering inside the cell by damaging cell wall or membrane causing loss of intracellular material, finally resulting into bacterial death (Xu et al., 2016). The results of present study have shown higher zone of inhibition when the plant extracts were tested against the pathogenic bacteria. The results where compared with the available literature. In a study, the antimicrobial activity of standard Ciprofloxacin against E. coli and S. aureus was $10 \mathrm{~mm}$ and $7 \mathrm{~mm}$ respectively (Balogun and Tunde 2020).

The antibacterial activity of neem leaf extract was almost $20 \mathrm{~mm}$ when tested against $E$. coli and $24 \mathrm{~mm}$ when Gentamycin was used against $E$. coli (Panchal et al., 2013). The methanol extract of Amla pulp gave a zone of inhibition of $19 \mathrm{~mm}$ and $16 \mathrm{~mm}$ against $E$. coli and $S$. aureus respectively. The standard of Amoxicillin and Amphotericin B gave a zone of inhibition of $23 \mathrm{~mm}$ and $21 \mathrm{~mm}$ respectively, when tested against $E$. coli (Vijayalakshmi et al., 2007). In the present study, the ethanol extract of Amla pulp has given a zone of inhibition of $15 \mathrm{~mm}$ and $14 \mathrm{~mm}$ against $S$. aureus and $E$. coli respectively. A zone of inhibition of 20 and $22 \mathrm{~mm}$ found when the ethanol extract of Amla 
pulp was tested against $K$. pneumonia and $S$. pyogens respectively. The available literature when compared to the present study clearly indicated that not much difference is seen when compared with the standard antibiotics. It is interesting to note that higher antibacterial activity was found in extract of plants prepared in ethanol, acetone and ethyl acetate (Fig.2), when assayed against $S$. aureus, S. pyogenes, E. coli, K. pneumonia and $S$. typhimurium. The plants extracts studied qualitatively through TLC have shown several bands representing presence of phytochemicals (Fig. 3). It has also been noted that the degree of band colour on TLC plates as a measure varies indicating broad range of biological activities. TLC is considered a cost-effective, simple, and easy-to-operate technique having many applications used in the development of new drugs from plant resources (Kumar et al., 2013). Several workers have reported presence of high content of varied bioactive compounds in amla, clove, neem and rose (Khan 2009, Rojas et al., 1992, Girish and Bhat 2008, Cendrowski et al., 2017, and Laxmi etal., 2017).

In the present study the results of contact bioautography have shown antibacterial activity of phytochemicals against $K$. pneumonia, suggesting that the selective extraction by appropriate solvents is very important for obtaining bioactive fractions of significance from natural sources (Boakye-Yiadom and Konning 1975). The contact bioautography gave a $16 \mathrm{~mm}$ zone of inhibition of ethanol extract of $E$. officinalis against $K$. pneumonia. The ethanol extracts of $A$. indica and $R$. indica gave a zone of $12 \mathrm{~mm}$ and $13 \mathrm{~mm}$ respectively against $K$. pneumonia. The results of contact bioautography of acetone extract of $E$. officinalis against $S$. aureus, S. typhimurium, K. pneumonia and S. pyogens were $16 \mathrm{~mm}, 13$ $\mathrm{mm}, 18 \mathrm{~mm}$ and $20 \mathrm{~mm}$ respectively. These results suggest the choice of solvent for extraction of the bioactive fraction is very important. Various reports showed that alkaloids and flavonoids, phenolics and tannins act as active antimicrobial compounds by precipitating microbial protein, which act as an inhibitor against pathogens (Chithrashree et al., 2014; Prasad et al., 2008). The antibacterial and antioxidant activities of the extract of $E$. officinalis and Terminalia bellirica which were found to be firmly associated with the total phenolic and flavanoid content of the extract have been reported (Badoni et al., 2016). Alkaloids are also important group of differently distributed chemicals of biologically and commercially powerful natural products. The need for extensive research on alkaloids for drug development and discovery has been suggested (Cordell et al., 2001). The present study based on the results has suggested that ethanol, acetone and ethyl acetate extracts of plants extract had better antibacterial activity than hexane, chloroform and dichloromethane against tested Grampositive and Gram-negative pathogens. The phytochemicals present in the extract also confirmed antibacterial activity against $K$. pneumoniae. The presence of phytochemicals can be valuable substance for the production of pro health preparations.

\section{Acknowledgements}

Authors are thankful to the Head of Institution, Amity Institute of Biotechnology, Amity University, Noida for his constant support and encouragement to carry out the proposed study. A sincere thanks to Dr. Sanjay Pathak of Narendra Dev University of Agriculture and Technology, Faizabad for providing the plant material. The work is part of Ph.D. programme of Ankita Saxena. We wish to express special thanks to fellow colleagues for their all-time cooperation.

\section{References}

Atawodi, S.E. and J.C. Atawodi: Azadirachta indica (neem): A plant of multiple biological and pharmacological activities. Phytochem. Rev., 8, 601-620 (2009).

Badoni, H., P. Sharma, S.M. Waheed and S. Singh: Investigation of phytochemical composition, evaluation of antioxide and antibacterial activity and toxicity study of Emblica officianilis and Terminalia bellarica fruits. Asian J. Pharma. Clin. Res., 9, 96-102 (2016).

Balogun, O.D. and G.S. Tunde: Antimicrobial activities of pure honey against some bacteria in wound infection. Int. J. Innova. Res. Adv. Studies (IJIRAS), 7, 146-149 (2020).

Banna, Q.R., R. Parveen and Md.J. Iqbal: Growth inhibitory effect of ethanolic neem leaves extract of Klebsiella, Salmonella and Styphylococcus aureus. Bang. J. Pharmacol., 9, 347-350 (2014).

Bauer, A.W, W.M. Kirby, J.C. Sherris and M. Turck: Antibiotic susceptibility testing by a standardized single disk method. Am. J. Clin. Pathol., 45, 493-496 (1966).

Boakye-Yiadom, K. and G.H. Konning: Incidence of antibacterial activity in the Connaracea. Planta Med., 28, 397-400 (1975).

Cendrowski, A., A. Ścibisz, M. Mitek, M. Kieliszek and J.K. Ostek: Profile of the phenolic compounds of Rosa rugosa petals. J. Food Quality, 2017, Article ID 7941347. https://doi.org/10.1155/2017/7941347 (2017).

Chew, A.L., J.J. Jessica and S. Sasidharan: Antioxidant and antibacterial activity of different parts of Leucas aspera. Asian Pac. J. Trop. Biomed., 2, 176-180 (2012)

Chithrashree, N.K. Murthy and C. Srinivas: Phytochemical screening and in vitro assessment of antimicrobial and antioxidant potential of Andrographis serpyllifolia- An endemic medicinal plant from South India. Int. J. Adv. Res., 2, 917-928 (2014).

Cordell, G.A., M.L. Quinn-Beattie and N.R. Farnsworth: The potential of alkaloids in drug discovery. Phytother. Res., 15, 183-205 (2001).

Everest, P., J. Ketley, S. Hardy, G. Douce, S. Khan, J. Shea, D. Holden, D. Maskell and G. Dougan: Evaluation of Salmonella typhimurium mutants in a model of experimental gastroenteritis. Infect. Immu., 67, 2815-2821 (1999).

Farjana, A., N. Zerin and Md.S. Kabir: Antimicrobial activity of medicinal plant leaf extracts against pathogenic bacteria. Asian Pac. J. Trop. Dis., 4 (Suppl 2): S920-S923 (2014)

Girish, K. and S.S. Bhat: Neem-A green treasure. eJ Bio., 4, 102-111 (2008).

Hessling, M., J. Feiertag and K. Hoenes: Pathogens provoking most deaths. Biosci. Biotech. Res. Comm., 10, 1-7 (2017).

Jagatheeswari, D., J. Deepa, H.S. Ali and P. Ranganathan: Acalypha indica $L$ an important medicinal plant: $A$ review of its traditional uses, and pharmacological properties. Int. J. Res. Bot., 3, 19-22 (2013).

Khan, K.H.: Roles of Emblica officinalis in Medicine -AReview. Bot. Res. Int., 2, 218-228 (2009).

Koday, N.K., G.S. Rangaiah, V. Bobbarala and S. Churukuri: Bactericidal activities of different medicinal plant extracts against ocular pathogens viz. Corynebacterium macginleyi. Drug Invention Today, 2, 5-7 (2010). 
Kumar, S., K. Jyotirmayee and M. Sarangi: Layer Chromatography: A tool of biotechnology for isolation of bioactive compounds from medicinal plants. Int. J. Pharm. Sci. Rev. Res., 18, 126-132 (2013).

Laxmi, S.K, D.D. Sandhya, S. Geetha and S.M. Lakshmi: Biochemical and antimicrobial analysis of Rose petals (Rosa indica). Eur. J. Pharm. Med. Res., 4, 637-640 (2017).

Lewis, H.W. and C.J. Moody: Experimental Organic Chemistry. Principles and Practice. Wiley Blackwell, pp. 159-173 (1989).

Lim, J.Y, J. Yoon and C.J. Hovde: A brief overview of Escherichia coli 0157:H7 and its plasmid 0157: J. Microbiol. Biotechnol., 20, 5-14 (2010).

Majeed, M., B. Bhat, A.N. Jadhav, J.S. Srivastava and K. Nagabhushanam: Ascorbic acid and tannins from Emblica officinalis Gaertn. Fruits- A revisit; J. Agric. Food Chem., 57, 220$225(2009)$.

Nishan, M. and P. Subramanian: Pharmacological and nonpharmacological activity of Azadirachta indica (Neem) - A review. Int. J. Biosc., 5, 104-112 (2014).

Parasuraman, S., G.S. Thing and S.A. Dhanaraj: Polyherbal formulation: Concept of Ayurveda. Pharmacogn. Rev., 8, 73-80 (2014).

Panchal, P., H. Bajaj and S. Maheshwari: Azadirachta indica (NEEM): antibacterial effects against Escherichia coli and Salmonella. Guru Drone J. Phar. Res., 1, 18-21 (2013).

Prasad, R.N., S. Viswanathan, J.R. Devi, V. Nayak, V.C. Swetha, B.R. Archana, N. Parthasarthy and J. Rajkumar: Preliminary phytochemical screening and antibacterial activity of Samanea saman. J. Med. Plants Res., 2, 268-270 (2008).

Raja, R. and R.M. Sreenivasulu: Medicinal plants secondary metabolites used in pharmaceutical importance -An overview. World J. Pharm. Pharm. Sci., 4, 436-447 (2015).

Ravva, S.V. and A. Korn: Effect of neem (Azadirachta indica) on the survival of Escherichia coli 0157:H7 in dairy manure. Int. J. Environ. Res. Publ. Hlth., 12, 7794-7803 (2015).

Rahman, S., M.M. Akbor, A. Howlader and A. Jabbar: Antimicrobial and cytotoxic activity of the alkaloids of Amlaki (Emblica officinalis). Pak. J. Biol. Sci., 12, 1152-1155 (2009).

Ryan, K.J. and C.G. Ray: Sherris Medical Microbiology. $4^{\text {th }}$ Edn., McGraw Hill. (2004).

Rojas, A., L. Hernandez, R. Pereda-Miranda and R. Mata: Screening for antimicrobial of crude drug extracts and pure natural products from Mexican medicinal plants, J. Ethnopharmacol., 35, 275-285(1992).

Saeed, S. and P. Tariq: Antibacterial activities of Emblica officinalis and Coriandrum sativum against Gram negative urinary pathogens.
Pak. J. Pharm. Sci., 20, 32-35 (2007).

Saeed, S. and P. Tariq: In-vitro antibacterial activity of clove against Gram negative bacteria. Pak. J. Bot., 40, 2157-2160 (2008).

Sahoo, A.M., C.K. Chakraborti, S. Nayak and S. Kayal: In-vitro antibacterial activity study of Rosa indica Linn. leaves extracts. Int. Res. J. Pharm., 2, 180-182 (2011).

Shohayeb, M., E.L.S. Saleh, S.A. Bazaid and I.A. Maghrabi:Antibacterial and antifungal activity of Rosa damascena MILL. Essential oil, different extracts of rose petals. Global J. Pharmaco., 8, 1-7 (2014).

Sofia, P.K., R. Prasad, V.K. Vijay and A.K. Srivastava: Evaluation of antibacterial activity of Indian spices against common foodborne pathogens. Int. J. Food Sci. Technol., 42, 910-915(2007).

Srivastava, J., J. Lambert and N. Vietmeyer: Medicinal plants: An expanding role in development. World Bank Technical Papers No. 320. (1996). https://doi.org/10.1596/0-8213-3613-4

Todar, K.: Pathogenic E. coli: Online Textbook of Bacteriology. University of Wisconsin-Madison Department of Bacteriology (2007).

Tong, S.Y., J.S. Davis, E. Eichenberger, T.L. Holland and V.G. Fowler: Staphylococcus aureus infections: epidemiology, pathophysiology, clinical manifestations, and management. Clin. Microbiol. Rev., 28, 603-661 (2015).

Upadhyay, A., I. Upadhyaya, A.K. Johny and K. Venkitanarayanan: Combating pathogenic microorganisms using plant-derived antimicrobials: A mini review of the mechanistic basis. BioMed. Res. Int., 2014, (2014). Article ID 761741. https:// doi.org/ 10.1155/ 2014/761741

Uzzaman, S.: Pharmacological activities of neem (Azadirachta indica): A review: Int. J. Pharma. Clin. Res., 1, 1-4 (2019).

Vijayalakshmi, S., V.A. Kumar, D. Anju, P. Gunasundari, P. Moorthy and A.K. Chandrasekharan: Comparative antimicrobial activities of Emblica officinalis and Ocimum sanctum. Anc. Sci. Life, 27, 1-6 (2007).

Wang, H., M. Naghavi, C. Allen, R.M. Barber, Z.A. Bhutta,A. Carter, D.C. Casey and F.J. Charlson: Global, regional, and national life expectancy, all-cause mortality, and cause-specific mortality for 249 causes of death, 1980-2015: A systematic analysis for the Global Burden of Disease Study 2015. The Lancet, 388, 1459-1544 (2016).

Xu, J.G., T. Liu, Q.P. Hu and X.M. Cao: Chemical composition, antibacterial properties and mechanism of action of essential oil from clove buds against Staphylococcus aureus. Molecules, 21, 1194 (2016). https://doi.org/10.3390/molecules21091194 